\title{
COMPARATIVE EVALUATION OF OSSEODENSIFICATION EFFECT ON PERI-IMPLANT STRAIN WHILE LOADING A FOUR UNIT CERAMIC FIXED PARTIAL DENTURE (IN VITRO STUDY)
}

\author{
Abdulla A. Abu Ghonaim ${ }^{1}{ }_{B D s}$ Samir I. Bakry²$P H D$, Amal E. Eldin ${ }^{3} P H D$.
}

\section{ABSTRACT}

INTRODUCTION: Primary stability and bone quality are key factors in implant success in early stages of placement while osseointegration comes further on.

OBJECTIVES: The aim of this study was to compare the effect of osseodensification on peri-implant strain during functional loading of a 4-unit monolithic zirconia bridge as well as its effect on primary stability and insertion torque.

MATERIALS AND METHODS: Sixteen IS-II active implants were used in this study; the implants were divided into 2 groups. Group (A) were placed in conventionally drilled osteotomy sites with progressive subtractive enlargement and Group (B) were placed in osseo-densified osteotomy sites. All implants were inserted in unicortical polyurethane test blocks mimicking medium quality bone while recording insertion torque and implant stability quotient (ISQ) using Osstell for all implants. Each block contained two parallel implants carrying a 4-unit fixed partial denture (FPD). FPD were cemented then thermocycled for 5000/cycle and mechanically loaded at $100 \mathrm{~N}, 2.5 \times 10 * 5$ cycles. A load of $400 \mathrm{~N}$ and $600 \mathrm{~N}$ and $800 \mathrm{~N}$ was applied at connector areas in FPD. Strain gauges were connected to strain meter to record the peri-implant strain for both implants in all groups.

RESULTS: Regarding insertion torque and peri-implant insertion torque strain Group (A) had significantly lower values than group B (p<0.05) while insignificant Osstell values. Concerning peri-implant strain after loading group A had significantly higher strain values than Group (B) ( $<<0.05$ ).

CONCLUSION: Osseodensification drilling protocol increased insertion torque values and peri-implant insertion torque strain in comparison to conventional drilling protocol while decreasing peri-implant strain after loading.

KEYWORDS: Osseodensification; primary stability; implants; in vitro;

RUNNING TITLE: osseodensification effect on peri-implant strain

1. B.D.S., Faculty of Dentistry, Pharos University

2. Professor of Professor of Conservative Dentistry, Faculty of Dentistry, Alexandria University

3. Professor of Dental Biomaterials, Faculty of Dentistry, Pharos University

* Corresponding Author:

Email: Dr.abdulla.ghonaim@gmail.com

\section{INTRODUCTION}

In 1978, Brånemark presented a two-stage threaded titanium root-form implant; he developed and tested a system using pure titanium screws which he termed fixtures. Originally the implants were cylindrical but later on became tapered. Due to the success of dental implants to restore missing teeth they have become a crucial part in dentistry (1). Crestal bone loss dictated further improvements and understanding of biomechanics. Later on more improvements in thread design (2), surface treatment (3) and surgical protocol (4) have been used to increase success, decrease the time of osseointegration and decrease crestal bone loss.

Many techniques have been used to increase peri-implant bone quality. Summers, R. B. (1994), used small cylindrical hand instruments called osteotomes were used to compact the bone laterally and apically (5) but resulted in unfavourable effect on primary stability and mild concussion or headaches to the patient (6). Lee, Ernesto \& Anitua, Eduardo (2006), used rotary expanders in increasing primary stability and bone quality (7). Also, many authors suggested undersizing the osteotomy site or omitting bone tapping has also shown good results in enhancing primary stability and bone quality (8) but some reported bone pressure necrosis (9). Degidi et al. (2017), introduced the stepped osteotomy preparation which involved undersizing the apical portion and standard drilling the coronal portion has been also used but took longer time (10). Finally reaching a new approach by using nonextraction osteotomy site preparation has been used by osseodensifying drills concept $(11,12)$.

Osseodensification technique is a novel, biomechanical and non-extraction osteotomy preparation technique that was introduced in 2012 by Huwais, Salah (Jackson, MI, US). Osseodensification technique does not excavate bone but simultaneously compacts, condenses and autografts the particulate bone in an outward direction to create the osteotomy, thereby preserving vital bone tissue. Thereby increasing the bone density in the peri-implant areas and 
improving the implant mechanical stability (13). It uses specialized high-speed densifying burs (Densah ${ }^{\mathrm{TM}}$ ) fabricated by (Versah LLC) rotating in a counter clockwise motion with ambient irrigation to prepare osteotomy and autograft bone in the phase of plastic deformation. This results in an expanded osteotomy with preserved and dense compacted bone tissue that helps maintain ridge integrity and allows implant placement with superior stability (14).

Enhancing the implant bed is crucial to accommodate occlusal forces falling on the implant supported fixed partial denture (FPD). As seen in literature, the stress distribution around an implant is influenced by different biomechanical factors. Biomechanically, the stress an implant transmits to the bone is influenced by the implant design, recipient bone and osteotomy site preparation(15). A few clinical studies have reported higher failure rates of implants placed in lowdensity bone (16). Due to the intimate contact between the implant and the bone as load falls on the (FPD) strain is formed at the crestal bone surrounding the implant fixture causing remodelling of bone (17).

This in-vitro study was conducted to test the hypothesis that the osseodensification drilling protocol (ODP) vs conventional drilling protocol (CDP) would affect the periimplant strain in a 4-unit screw retained full anatomy zirconium fixed partial denture (FPD) to decrease periimplant strain. The null hypothesis is that osseodensification has no effect on primary stability or peri-implant strain.

\section{MATERIALS AND METHODS}

Materials:

- Cellular Unicortical Polyurethane test blocks (Sawbones, Sweden)

- Osseodensification (Densah ${ }^{\mathrm{TM}}$ ) Drills (VT5 kit) (Versah, USA)

- IS-full kit surgical kit (Neobiotech Co.,Ltd, SEOUL Rep. of Korea)

- 16 Neo Biotech IS II Active Fixture implants (Neobiotech Co.,Ltd, SEOUL Rep. of Korea)

- 16 Standard straight implant abutments (Neobiotech Co.,Ltd, SEOUL Rep. of Korea)

- D-scan spray (Dentify, Germany)

- Zirconia blocks (ZIRCON.X) (President Dental GmbH Zehentstadelweg, Germany)

- Strain gauge adhesive (CC-33A) (Kyowa, Tokyo, Japan)

- Resin cement (G-Cem, Tokyo, Japan)

Equipment:

- Microtome (Buehler IsoMet, Illinois, USA)

- Dental Parallelometer (SILFRADENT SRL, Sofia, Italy)

- Strain Gauges (KFGS-2N-120-C1-11L1M2R) (Kyowa, Tokyo, Japan)

- Strain meter (Tokyo Sukki Kenkyuji Co. Ltd. Tokyo, Japan)

- Osstell ${ }^{\mathrm{TM}}$ (Gothenburg, Sweden)

- Shining 3D optical scanner (SHINING 3D Tech. Co., Ltd, Hangzhou, China)

- IMES-ICORE 250 I CAM Milling Machine (imes-icore ${ }^{\circledR}$ GmbH, Eiterfeld, Germany)

- Sintering Furnace (MIHM-VOGT GmbH \& Co., Blankenloch, Germany)
- Vacuum Porcelain Furnace (GmbH Rodenbacher Chaussee, Wolfgang, Germany)

- Custom Static Load Device (Dr. Amir Azer, Alexandria, Egypt)

- Thermocycling machine (Biomaterial Department, Alexandria, Egypt)

- Cyclic loading device (Biomaterial Department, Alexandria, Egypt)

- Universal Testing Machine (Kyocera Unimerco Tooling GmbH, Neuss Hammfelddamm, Germany)

- Custom Jig and loading plunger (Dr.Khaled Ibrahim,Dr.Abdulla Abu Ghonaim, Alexandria, Egypt)

\section{Methods:}

Preparation of test blocks

Cellular rigid Polyurethane test blocks were used as an alternative test medium simulating medium quality human bone. The dimensions of the rigid Polyurethane (PU) foam for comparative testing blocks are $170 \mathrm{~mm}$ x $120 \mathrm{~mm}$ x 40 $\mathrm{mm}$ and 20 pounds per cubic foot (PCF) density laminated with $2 \mathrm{~mm} 40$ PCF solid foam.

The block was sawed using an electric saw. Eight smaller blocks were obtained with the following dimensions (55 mm in length; 40mm in width and $42 \mathrm{~mm}$ in height).

Each block was marked by a pencil to mark the position of the drilling, the distance between the 2 implants, the position the strain gauges (SGs) and the place of the mesial implant (MI) and distal implant (DI).

The implants were marked $26 \mathrm{~mm}$ apart, the SGs were marked at four different positions (A, B) around the DI and (C, D) around the $\mathrm{MI}$ for the insertion torque strain measurements and at 1 to 8 for the load application measurements. Around the position of the implants a $7 \mathrm{~mm}$ circle was drawn to replicate the distance away from the implant center, the SGs were placed averagely $1.25 \mathrm{~mm}$ from the edges of the implant (Figure 1).

\section{Grouping according to variable allocation}

Blocks were randomly divided into two groups; one control and one test group (4 blocks each) according to the method of implant bed preparation used.

Group A CDP: Monolithic screw retained 4 unit full anatomy zirconia bridge FPD supported on the Neo Biotech IS II Active Fixture implants $(4.5 \times 10 \mathrm{~mm})$ for $\mathrm{MI}$ and $(4.5 \times 8.5 \mathrm{~mm})$ for DI.

Implants placed in test blocks using CDP.

Group B ODP: Monolithic screw retained 4 unit full anatomy zirconia bridge FPD supported on the Neo Biotech IS II Active Fixture implants $(4.5 \times 10 \mathrm{~mm})$ for $\mathrm{MI}$ and (4.5x8.5mm) for DI.

Implants placed in test blocks using ODP.

\section{Preparation and drilling of the test blocks}

\section{Implant placement}

For Group A (CDP)

1. First the parallelometer was set to $1,500 \mathrm{rpm}$ in clockwise motion and pilot drill size $\varnothing 2.3 \mathrm{~mm}$ was attached to the vertical arm. The vertical arm was locked in position so that it will only allow upward and downward movement (Figure 2). 
2. The polyurethane block was then attached to the horizontal adjustable table and the block surface was water balanced to ensure that it was perpendicular to the vertical arm then the horizontal arm was locked.

3. The polyurethane block was centralized over the drilling point of the MI position with the $10 \mathrm{~mm}$ stopper attached to the pilot drill and then drilling in bouncing motion till full length while cooling using a saline syringe. The block was then centralized on the DI position with the $8.5 \mathrm{~mm}$ stopper attached to the pilot drill and then drilling in bouncing motion till full length while cooling using a saline syringe.

4. Followed by drills $\varnothing 3 \mathrm{~mm}, \varnothing 3.5 \mathrm{~mm}$ and $\varnothing 4 \mathrm{~mm}$ in the same manner following the manufacturer instructions.

5. Four SGs were adhered to position A, B, C, D and attached to the strain meter. The block was then attached to the horizontal table and water balanced again and locked. The strain meter was calibrated to $0 \mu \varepsilon$ (microstrain).

6. The contra-angle fixture driver was then attached to the vertical arm and then the implant ( $\varnothing 4.5 \times 10 \mathrm{~mm})$ was inserted in the mesial hole and the implant $(\varnothing 4.5 \times 8.5 \mathrm{~mm})$ for the distal hole.

7. The last thread was manually torqued to observe and record the final torque using the torque wrench. The strain meter reading was recorded when the implant was flushed with the block surface.

8. The smart peg was then torqued into the MI and DI at 8$10 \mathrm{Ncm}$ and the ISQ was measured.

9. This was repeated for the next 3 blocks of group A. Eight straight abutments were torqued to $35 \mathrm{Ncm}$.

For Group B (ODP)

1. Repeat step $1+2$ as group (A)

2. The parallelometer is now reset to $1,500 \mathrm{rpm}$ in counter clockwise motion and then (Densah ${ }^{\mathrm{TM}}$ ) drills VT1525, VT2535 and VT3545 were used to drill MI position then drilling in bouncing motion till the $10 \mathrm{~mm}$ mark consecutively. The block was then centralized on the DI position then drilling in bouncing motion till just passed the $8 \mathrm{~mm}$ mark consecutively.

3. Repeat steps $5+6+7+8$

4. This was repeated for the next 3 blocks of group B. Eight straight abutments were torqued to $35 \mathrm{Ncm}$.

\section{FPD Fabrication and Cementation}

1. SGs on the block surface were removed.

2. The fixed abutments were sprayed with D-scan and placed into the Shining 3D (optical scanner).

3. The abutments were scanned then die scanned.

4. The FPD was then designed using exocad. Full contoured virtual design of the four units FPD from the first upper premolar to the upper second molar.

5. All FPD were identical in design and dimensions with $40 \mu \mathrm{m}$ cement gap, connector size more than $4 \times 4$ and cylindrical in shape. The same design was used for all FPDs with a separate scan for every abutment to insure accurate fitting surfaces and flat area position.

6. The designs were then milled using Imes Icore cortex 250i CAD/CAM using zirconia blocks (ZIRCON.X) to full anatomy.

7. The FPDs were then sintered in the sintering furnace and glazed in the porcelain furnace.
8. The abutments were then thoroughly cleaned with bristle brushes on low-speed hand piece to clean remnant scan powder and each FPD tried onto its corresponding abutments to check fit.

9. The access hole was blocked with Teflon. The G-cem resin cement was applied to the fitting surfaces of the crown and the FPDs then placed on both abutments simultaneously. A force applied using a static load machine of $5 \mathrm{~kg}$ for 10 minutes and excess removed with blade no.15.

10. The Teflon was removed from the access hole and the FPD can now be unscrewed as a whole unit giving us a screw retained FPD.

Thermocycling and mechanical loading

1. All FPDs were stored have undergone thermocycling and mechanical loading proir to testing.

2. The FPDs were unscrewed and inserted into the baskets the thermocycler which was set to 5000 cycles, each cycle consisting of dwelling temperature of $\left(15^{\circ} \mathrm{C}, 45^{\circ} \mathrm{C}\right)$ and dwelling time of $5 \mathrm{~s}$ and a rest period of 30 s which corresponds to simulation of 6 month in function. The FPD's were then removed.

3. After thermocycling the FPDs were then screwed back into there corresponding implants to $35 \mathrm{~N}$ in the polyurethane block.

4. The polyurethane blocks were then stabilized to the horizontal table using a custom jig to hold the FPD in place while the mechanical loading device is operating.

5. A small sheet of rubber dam was adhered to the occlusal surface of the FPDs.

6. The FPDs were then subjected to $100 \mathrm{~N}$ mechanical loading for $2.5 \times 10^{5}$ cycles stimulating 6 month in function.

Application of Occlusal Loading on FPDs and strain measurements

1. Removal of the screwed FPDs

2. Eight SGs were adhered to the surface of the blocks at positions 1 to 4 around DI at (buccal, distal, palatal \& mesial respectively) and from 5 to 8 around the MI at (distal, palatal, mesial \& buccal respectively) using cyanoacrylate adhesive (CC-33A) (Figure 3).

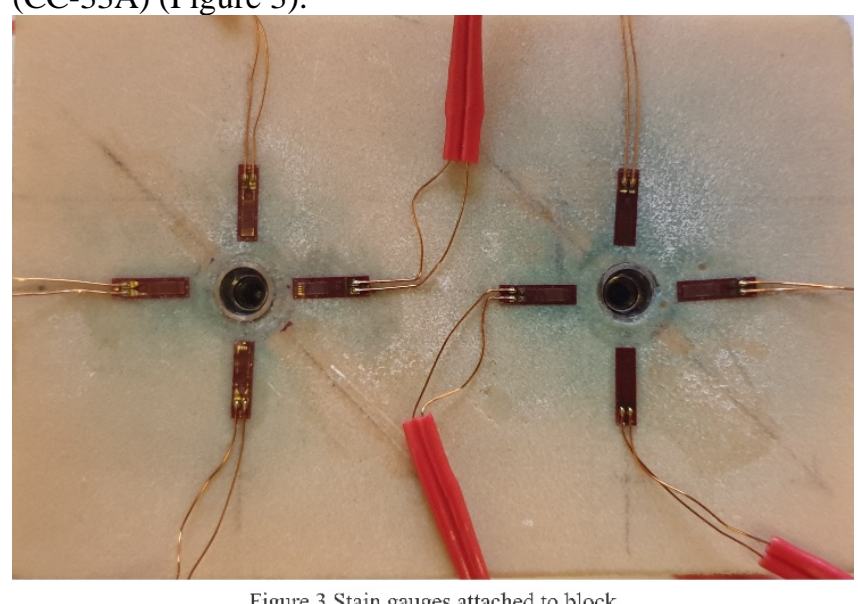

3. Screwed the FPD to $35 \mathrm{~N}$.

4. The SGs were then attached to the strain meter and calibrated to $0 \mu \varepsilon$.

5. The block was then placed into the jig and stabilized by tightening the screws and the loading plunger attached to the universal testing machine. 
6. The testing machine was set to compressive force ending at $800 \mathrm{~N}$ at a rate of $1 \mathrm{~mm} / \mathrm{min}$ and the vertical arm lowered to the bridge level then test initiated.

7. The load was placed on the mesial, middle and distal connectors 3 times and an average was taken (Figure 4).

- The strain meter readings were taken every $100 \mathrm{~N}$ and the SGs were re-calibrated after every measurement.

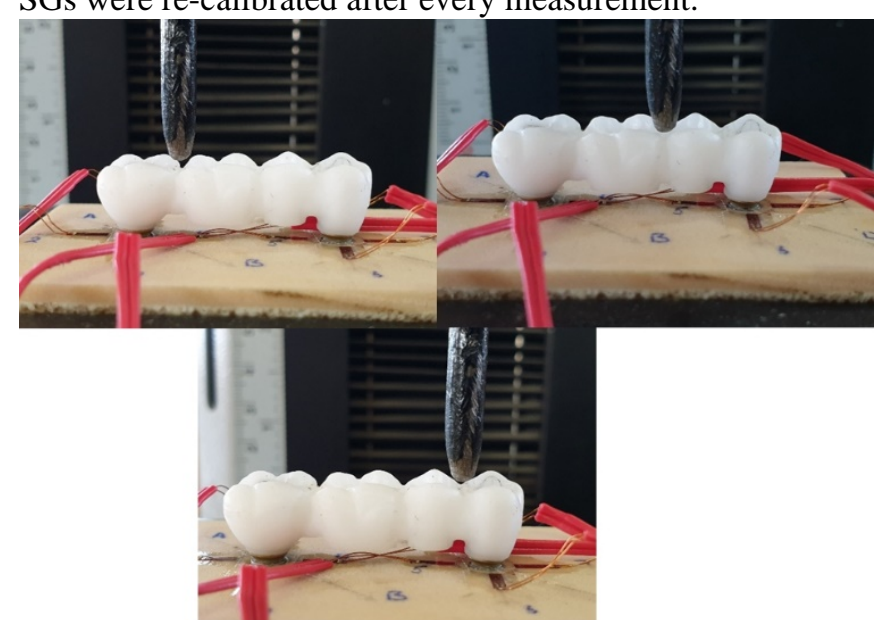

Figure 4: Different locations for load application A) Distal loading point B) Middle loading point C) Mesial loading point

\section{Statistical analysis of the data}

Data were fed to the computer and analyzed using IBM SPSS software package version 20.0. (Armonk, NY: IBM Corp). The Kolmogorov-Smirnov test was used to verify the normality of distribution Quantitative data were described using range (minimum and maximum), mean, standard deviation, median and interquartile range (IQR). Significance of the obtained results was judged at the $5 \%$ level.

\section{- The used tests were}

\section{1 - Student t-test}

For normally distributed quantitative variables, to compare between two studied groups

\section{RESULTS}

This study was conducted to evaluate the influence of two different drilling protocols on the strain generated around dental implants supporting a four-unit zirconium bridge replacing the teeth from the $1^{\text {st }}$ upper premolar to the $2^{\text {nd }}$ upper molar. Furthermore, the insertion torque values (ITV), periimplant insertion torque strain (PITS) and Osstell values (ISQ) were recorded for each implant during. The periimplant strain (PIS) generated while loading the FPD up to $800 \mathrm{~N}$ was recorded at 3 different loading points which are distal connector, middle connector and mesial connector.

\section{A. IT, PITS and Osstell value (ISQ): \\ a. Insertion torque}

When applying student t-test it was found that the CDP group had significantly lower values that ODP group with $\mathrm{P}=0.002$ for $\mathrm{DI}$ and $\mathrm{P}=0.001$ for $\mathrm{MI}$. The mean values of the CDP group ( $\mathrm{DI}=40 \mathrm{~N}, \mathrm{MI}=41.25 \mathrm{~N}$ ) were lower than the ODP group $(\mathrm{DI}=62.5 \mathrm{~N}, \mathrm{MI}=63.75 \mathrm{~N})$.

When applying student t-test it was found that when comparing the DI and $\mathrm{MI}$ in CDP group there was no significant difference $\mathrm{P}=0.638$, same with the $\mathrm{DI}$ and $\mathrm{MI}$ in the ODP $\mathrm{P}=0.789$. The mean values of DI
$(\mathrm{CDP}=40.0 \mathrm{~N}, \mathrm{ODP}=62.5 \mathrm{~N})$ were slightly lower than the $\mathrm{MI}(\mathrm{CDP}=41.25 \mathrm{~N}, \mathrm{ODP}=63.75 \mathrm{~N})$.

\section{b.Peri-implant Insertion Torque Strain:}

When applying student t-test it was found that the CDP group had significantly lower values that ODP group with $\mathrm{P}=0.001$ for DI and $\mathrm{P}=0.001$ for MI. The mean values of the CDP group, DI $(-597.8 \mu \varepsilon) \&$ MI $(-615.4 \mu \varepsilon)$ were lower than the ODP group, DI $(-763.3 \mu \varepsilon) \&$ MI $(-797.1 \mu \varepsilon)$ respectively. When applying student t-test it was found that when comparing the DI and MI in CDP group there was no significant difference $\mathrm{P}=0.416$, same with the $\mathrm{DI}$ and $\mathrm{MI}$ in the ODP $\mathrm{P}=0.118$. The mean values of the DI, CDP($597.8 \mu \varepsilon)$ ODP $(-763.3 \mu \varepsilon)$ were slightly lower than MI, CDP($615.4 \mu \varepsilon)$ ODP $(-797.1 \mu \varepsilon)$ respectively.

\section{c. Osstell Value (OV):}

When applying student t-test it was found that there was no significant difference between both groups with $\mathrm{p}=0.059$ for the DI and $\mathrm{p}=1$ for the MI. The mean values of the CDP group ( $\mathrm{DI}=74.0, \mathrm{MI}=76.25$ ) were nearly equal to the ODP group (DI=74.75, $\mathrm{MI}=76.25)$.

When applying student t-test it was found that when comparing the DI and MI in CDP group there was a significant difference $\mathrm{P}=0.006$, same with the $\mathrm{DI}$ and $\mathrm{MI}$ in the ODP $\mathrm{P}=0.005$. The mean values of the $\mathrm{DI}(\mathrm{CDP}=74.0$, $\mathrm{ODP}=74.75)$ were slightly lower than the $\mathrm{MI}(\mathrm{CDP}=76.25$, $\mathrm{ODP}=76.25)$.

B. Peri-implant strain post loading FPD up to $800 \mathrm{~N}$ :

- A load up to $800 \mathrm{~N}$ was applied on 8 FPDs at distal, middle and mesial connector and the readings from the 8 SGs adhered to the block surface were recorded every $100 \mathrm{~N}$. For the eight blocks $(\mathrm{CDP}=4$ \& $\mathrm{ODP}=4)$ all three loading points were repeated 3 times and the strain for each SG was calculated. This result was then further averaged with the other 3 blocks in the same group and a mean peri-implant strain (PIS) for DI and MI for each loading point was calculated at loads $400 \mathrm{~N}, 600 \mathrm{~N}$ and $800 \mathrm{~N}$.

- The highest PIS for distal connector loading point (DCLP) was at SG no.4 $(-2127.11 \mu \varepsilon,-3262.59 \mu \varepsilon$ and $-4216.54 \mu \varepsilon)$ for CDP and $(-1225.53 \mu \varepsilon,-1926.33 \mu \varepsilon \&-2605.62 \mu \varepsilon)$ for ODP at $400 \mathrm{~N}, 600 \mathrm{~N}$ and $800 \mathrm{~N}$ respectively. It was observed that there were higher values for distal implant peri-implant strain (DIPIS)and higher PIS for CDP group compared to ODP group. (Table 1)

- The highest PIS for middle connector loading point (MCLP) was at SG no.5 $(-1537.99 \mu \varepsilon,-2358 \mu \varepsilon \&$ $3310.49 \mu \varepsilon)$ for $\mathrm{CDP}$ and $(-933.10 \mu \varepsilon,-1547.48 \mu \varepsilon$ \& $-2163.61 \mu \varepsilon)$ for ODP at $400 \mathrm{~N}, 600 \mathrm{~N}$ and $800 \mathrm{~N}$ respectively. It was observed that there were higher values for mesial implant peri-implant strain (MIPIS) and higher PIS for CDP group compared to ODP group.

- The highest PIS for mesial connector loading point (MsCLP) was at SG no.5 (-2370.51 $\mu \varepsilon,-350946 \mu \varepsilon \&-$ $4484.14 \mu \varepsilon)$ for $\mathrm{CDP}$ and $(-1278.11 \mu \varepsilon,-1916.94 \mu \varepsilon$ \& $-2642.75 \mu \varepsilon)$ for ODP at $400 \mathrm{~N}, 600 \mathrm{~N}$ and $800 \mathrm{~N}$ respectively. It was observed that there were higher values for MIPIS and higher PIS for CDP group compared to ODP group. 
Table 1 :Table showing PIS at positions 1-8 at distal connector loading point at loads $400 \mathrm{~N}, 600 \mathrm{~N}$ and $800 \mathrm{~N}$

\begin{tabular}{|c|c|c|c|c|c|c|c|c|c|}
\hline \multicolumn{7}{|c|}{ Distal connector loading point } \\
\hline Group & Force & \multicolumn{7}{|c|}{ Distal implant (-) } \\
$\begin{array}{c}\text { SG } \\
\text { position }\end{array}$ & & 1 & 2 & 3 & 4 & 5 & 6 & 7 & 8 \\
\hline CDP & $400 \mathrm{~N}$ & 1507.08 & 1523.45 & 1525.10 & 2127.11 & 565.64 & 391.98 & 490.69 & 422.15 \\
\cline { 2 - 12 } & $600 \mathrm{~N}$ & 2494.37 & 2536.67 & 2456.99 & 3262.59 & 872.35 & 613.01 & 763.93 & 678.63 \\
\cline { 2 - 12 } & $800 \mathrm{~N}$ & 3373.87 & 3426.72 & 3327.36 & 4216.54 & 1185.37 & 846.77 & 1026.41 & 922.71 \\
\hline ODP & $400 \mathrm{~N}$ & 672.92 & 797.25 & 1009.43 & 1225.53 & 358.38 & 230.58 & 311.14 & 189.12 \\
\cline { 2 - 11 } & $600 \mathrm{~N}$ & 1210.64 & 1359.79 & 1671.82 & 1926.33 & 533.61 & 361.96 & 475.85 & 306.48 \\
\cline { 2 - 11 } & $800 \mathrm{~N}$ & 1842.25 & 1981.41 & 2285.39 & 2605.62 & 714.64 & 500.51 & 635.52 & 449.62 \\
\hline
\end{tabular}

(-): Values in this column are negative

Table 2 : showing descriptive statistics, mean \pm SD, comparison between CDP and ODP effect on average periimplant microstrain $(\mu \varepsilon)$ around mesial and distal implants upon loading distal connector in FPDs up to $800 \mathrm{~N}$

\begin{tabular}{|c|c|c|c|c|c|c|}
\hline \multicolumn{7}{|c|}{ Distal Connector loading point } \\
\hline $\begin{array}{l}\text { Implant } \\
\text { position }\end{array}$ & $\begin{array}{c}\text { Force } \\
\text { (N) }\end{array}$ & & $\begin{array}{l}\text { CDP } \\
(n=4) \\
(\mu \varepsilon) \\
(-)\end{array}$ & $\begin{array}{c}\text { ODP } \\
(n=4) \\
(\mu \varepsilon) \\
(-)\end{array}$ & $\mathbf{t}$ & $\mathbf{p}$ \\
\hline \multirow{6}{*}{ 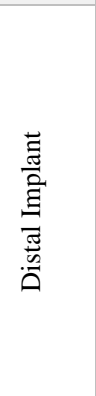 } & \multirow[t]{2}{*}{$400 N$} & Min. - Max. & $\begin{array}{c}1507.1- \\
2127.1\end{array}$ & $\begin{array}{l}672.9- \\
1225.5\end{array}$ & \multirow[t]{2}{*}{$3.822^{*}$} & \multirow[t]{2}{*}{$0.009^{*}$} \\
\hline & & Mean \pm SD & $\begin{array}{c}1670.7 \pm \\
304.4\end{array}$ & $\begin{array}{c}926.3 \pm \\
243.1\end{array}$ & & \\
\hline & \multirow[t]{2}{*}{$600 N$} & Min. - Max. & $\begin{array}{c}2457.0- \\
3262.6\end{array}$ & $\begin{array}{c}1210.6- \\
1926.3\end{array}$ & \multirow[t]{2}{*}{$4.578^{*}$} & \multirow[t]{2}{*}{$0.004^{*}$} \\
\hline & & Mean \pm SD & $\begin{array}{c}2687.7 \pm \\
384.7\end{array}$ & $\begin{array}{c}1542.1 \pm \\
320.2\end{array}$ & & \\
\hline & \multirow[t]{2}{*}{$800 \mathrm{~N}$} & Min. - Max. & $\begin{array}{c}3327.4- \\
4216.5\end{array}$ & $\begin{array}{c}1842.3- \\
2605.6\end{array}$ & \multirow[t]{2}{*}{$5.196^{*}$} & \multirow[t]{2}{*}{$0.002^{*}$} \\
\hline & & Mean \pm SD. & $\begin{array}{c}3586.1 \pm \\
422.2\end{array}$ & $\begin{array}{c}2178.7 \pm \\
339.5\end{array}$ & & \\
\hline \multirow{6}{*}{ 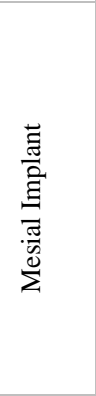 } & \multirow[t]{2}{*}{$400 \mathrm{~N}$} & Min. - Max. & $\begin{array}{l}392.0- \\
565.6\end{array}$ & $\begin{array}{c}189.1- \\
358.4\end{array}$ & \multirow[t]{2}{*}{$3.590 *$} & \multirow[t]{2}{*}{$0.011^{*}$} \\
\hline & & Mean \pm SD & $\begin{array}{c}467.6 \pm \\
77.31\end{array}$ & $\begin{array}{c}272.3 \pm \\
76.55\end{array}$ & & \\
\hline & \multirow[t]{2}{*}{$600 \mathrm{~N}$} & Min. - Max. & $\begin{array}{c}613.01- \\
872.35\end{array}$ & $\begin{array}{c}306.48- \\
533.61\end{array}$ & \multirow[t]{2}{*}{$4.092 *$} & \multirow[t]{2}{*}{$0.006^{*}$} \\
\hline & & Mean \pm SD. & $\begin{array}{c}731.98 \pm \\
112.13\end{array}$ & $\begin{array}{c}419.48 \pm \\
103.73\end{array}$ & & \\
\hline & \multirow[t]{2}{*}{$800 \mathrm{~N}$} & Min. - Max. & $\begin{array}{l}846.8- \\
1185.4\end{array}$ & $\begin{array}{c}449.6- \\
714.6\end{array}$ & \multirow[t]{2}{*}{$4.412 *$} & \multirow[t]{2}{*}{$0.005^{*}$} \\
\hline & & Mean \pm SD & $\begin{array}{c}995.3 \pm \\
146.5\end{array}$ & $\begin{array}{c}575.1 \pm \\
121.7\end{array}$ & & \\
\hline
\end{tabular}

(-): Values in this column are negative

t: Student t-test

$\mathrm{p}$ : $\mathrm{p}$ value for comparing between CDP and ODP

*: Statistically significant at $\mathrm{p} \leq 0.05$

\section{a.Distal connector Loading Point (DCLP)}

The table shows comparison between the average DIPIS in CDP group compared to the average DIPIS in ODP group. In the same table, the average MIPIS in CDP group is compared to average MIPIS in ODP group respectively at loads $400 \mathrm{~N}$, $600 \mathrm{~N}$ and $800 \mathrm{~N}$. The student t-test identified a significant difference between the average DIPIS at $400 \mathrm{~N}, 600 \mathrm{~N}$ and $800 \mathrm{~N}$ of $(\mathrm{P}=0.009),(\mathrm{P}=0.004)$ and $(\mathrm{P}=0.002)$ respectively and the average MIPIS of $(\mathrm{P}=0.011), \quad(\mathrm{P}=0.006)$ and $(\mathrm{P}=0.005)$ respectively. The highest average DIPIS was (-
$3586.1 \mu \varepsilon)$ for CDP and $(-2178.7 \mu \varepsilon)$ for ODP and the highest average MIPIS was $(-995.0 \mu \varepsilon)$ for CDP and $(-575.1 \mu \varepsilon)$ for ODP at 800 N. (Table 2, Figure 5).

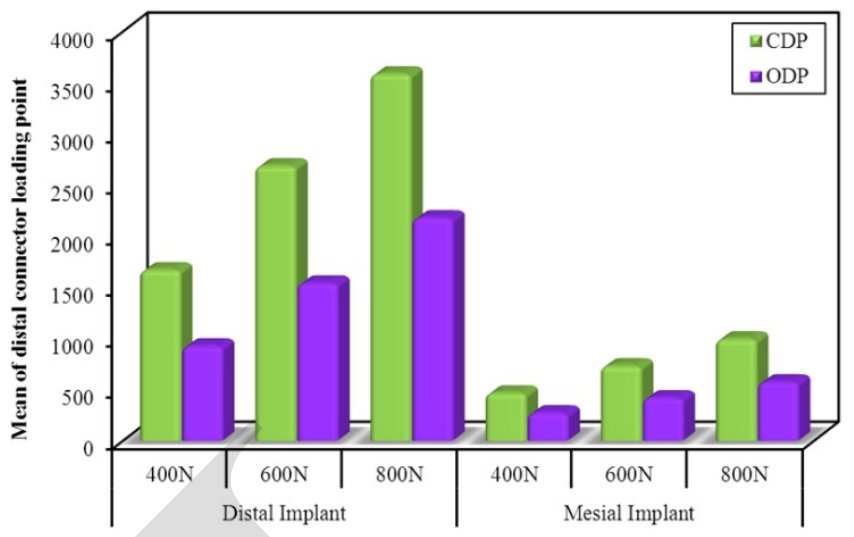

Figure 5: Bar graph showing comparison between CDP and ODP effect on average peri-implant microstrain $(\mu \varepsilon)$ around mesial and distal implants upon loading distal connector in FPDs up to $800 \mathrm{~N}$ $(-)$ : Values in this column are negative

a. The highest average strain reading was $(-4216.54 \mu \varepsilon)$ at $\mathrm{SG}$ no.4 for CDP and $(-2605.62 \mu \varepsilon)$ at SG (4) for ODP group at $800 \mathrm{~N}$ (Table 2).

b. Middle connector loading point (MCLP)

The table shows comparison between the average DIPIS in CDP group compared to the average DIPIS in ODP group. In the same table, the average MIPIS in CDP group is compared to MIPIS in ODP group respectively at loads $400 \mathrm{~N}, 600 \mathrm{~N}$ and $800 \mathrm{~N}$. The student t-test identified an insignificant difference between the average DIPIS at $400 \mathrm{~N}, 600 \mathrm{~N}$ and $800 \mathrm{~N}$ of $(\mathrm{P}=0.126),(\mathrm{P}=0.173)$ and $(\mathrm{P}=0.237)$ respectively. But the average MIPIS was insignificant for $400 \mathrm{~N}(\mathrm{P}=0.058)$ and significant for $600 \mathrm{~N}$ and $800 \mathrm{~N}$ of $(\mathrm{P}=0.046)$ and $(\mathrm{P}=0.043)$ respectively. The highest average DIPIS was $(-1691.4 \mu \varepsilon)$ for CDP and $(1387.6 \mu \varepsilon)$ for ODP and the highest average MIPIS was ($2580.1 \mu \varepsilon)$ for CDP and $(-1856.7 \mu \varepsilon)$ for ODP.

c. The highest average strain reading was $(-3310.49 \mu \varepsilon)$ at SG no.5 for CDP and $(-2163.61 \mu \varepsilon)$ at SG no.5 for ODP group at $800 \mathrm{~N}$.

\section{d. Mesial connector loading point (MsCLP)}

The table shows comparison between the average DIPIS in CDP group compared to the average DIPIS in ODP group. In the same table, the average MIPIS in CDP group is compared to MIPIS in ODP group respectively at loads $400 \mathrm{~N}, 600 \mathrm{~N}$ and $800 \mathrm{~N}$. The student t-test identified an insignificant difference between the average DIPIS at $400 \mathrm{~N}, 600 \mathrm{~N}$ and $800 \mathrm{~N}$ of $(\mathrm{P}=0.109), \quad(\mathrm{P}=0.078)$ and $(\mathrm{P}=0.066)$ respectively. But significant for average MIPIS at $400 \mathrm{~N}, 600 \mathrm{~N}$ and $800 \mathrm{~N}$ of $(\mathrm{P}=0.009), \quad(\mathrm{P}=0.004)$ and $(\mathrm{P}=0.003)$ respectively. The highest average DIPIS was $(-860.6 \mu \varepsilon)$ for CDP and ($579.8 \mu \varepsilon$ ) for ODP and the highest average MIPIS was ($3978.1 \mu \varepsilon)$ for CDP and $(-2326.2 \mu \varepsilon)$ for ODP.

The highest average strain reading was $(-4484.14 \mu \varepsilon)$ at SG no. 5 for CDP and $(-2642.75 \mu \varepsilon)$ at SG no.5 for ODP at $800 \mathrm{~N}$.

\section{DISCUSSION}

Bone density plays an important role in Implant stability (18) which influences the amount of bone-to-implant contact. Due to the importance of implant stabilization in bone of low density (19) it is vital to find new surgical techniques to 
improve the implant bed. In a prospective 5-year radiographic evaluation of crestal bone levels by Cochran et al. in the year 2009 , stated that $86 \%$ of crestal bone loss occurred in the early phase prior to loading suggesting that surgical trauma plays an important role marginal bone loss (20). The present study was conducted to evaluate the influence of two drilling protocols on the strain developed around dental implants.

For our in vitro study, Sawbones cellular polyurethane (PU) blocks 20 PCF $\quad\left(0.32 \mathrm{~g} / \mathrm{cm}^{3}\right)$ density laminated by $2 \mathrm{~mm} 40$ PCF $\left(0.64 \mathrm{~g} / \mathrm{cm}^{3}\right)$ solid PU were used as an in vitro model for low density bone replica of posterior maxilla. ASTM stated that the use of polyurethane blocks can be used to replicate the behavior of human cancellous bone (21). Normal bone mechanical properties according to $\mathrm{Li} \&$ Aspden's study (22), $0.31 \mathrm{~g} / \mathrm{cm}^{3}$ apparent density, fall within the range of Sawbones PCF20 cellular rigid polyurethane foam(23). Polyurethane blocks have been used by many authors in dental implants testing (24).

\section{Effect of osseodensification:}

Osseodensification is hypothesized to increase bone volume around the implant and in turn increasing PS and ITV which in turn help in secondary osseointegration. Huwais \& Meyer, suggested that ODP increased primary stability, bone mineral density, and the percentage of bone at the implant surface compared with CDP. ODP also preserved bone which seems to be inevitable with other procedures even with the use of osteotomes the peri-implant bone volume increased but bone damage was present causing persistent bone loss (25). These results were also backed by this study showing that osseodensification increased average ITV compared to conventional drilling.

Toia et al., suggested that drilling protocol it a key factor in implant survivability and that each patient requires a presurgical radiographic evaluation and the clinician tactile sensation in order to assess the bone quality and quantity to provide a suitable drilling protocol (26).

Effect of drilling protocol on peri-implant area preloading:

In our study, tapered implants inserted with ODP using tapered drills had a higher ITV than tapered implants inserted with CDP with cylindrical twist drills. These results were in line with Gehrke et al. (27).

Moreover, Farag et al. in the year 2018 tested ITV of 2 different implants in low density bone with average ITV (65N) for ODP and (52N) for CDP and concluded that CDP resulted in significantly lower ITV (28). These mean values were similar to our study's values for IT which were (63N) for ODP and $(40.5 \mathrm{~N})$ for CDP. Slete, Olin \& Prasad, compared ODP and another osseo-compaction procedure, Summers' osteotomes, and concluded that ODP had higher ITV and bone to implant contact (29).

As regards to PITS, as implants are inserted into an undersized osteotomy site a compressive strain was recorded in this study. This quality of strain, compressive strain, was similar to another study(30) but the quantity of it was incomparable to these studies due to changes in diameter, length and design of the implants, position, direction and calculation technique of the SGs.
Block et al., compared the PITS of 8 implants inserted in bovine bone and concluded that implant insertion produces higher horizontal strains than vertical strains with strains ranging from $948 \mu \varepsilon$ to $5524 \mu \varepsilon$. These results were higher than this study which ranged from $574.9 \mu \varepsilon$ to $823.6 \mu \varepsilon$. These higher strains maybe due to different position and direction of SGs or different length, diameter and design of implant or alteration osteotomy site preparation (30).

Effect of implant height on Peri-implant area preloading: In accordance with our results, Bataineh \& Al-Dakes in the year 2017, studied the effect of length on the primary stability of dental implants in bovine ribs and concluded that an increase in length resulted in an increase in primary stability with implants with the same diameter (31). Furthermore in our study, results showed increasing ITV and ISQ related to increasing length which shows agreement with Hsu et al. (32). In our study the longer implants had higher average OVs which agrees with Shiffler et al. (33). Nappo et al. investigated the effect of implant length, diameter and bone quality on ISQ readings and reached the same conclusion in the year 2019 (34).

As regard to PITS, the slight increase between the $8.5 \mathrm{~mm}$ DI and $10 \mathrm{~mm} \mathrm{MI}$, it was hypothesized that the further the implant was inserted into the block the more strain that developed crestally as the longer implant contacts the block for a higher surface area (30).

In contrast, Sarfaraz et al. reported that increased implant length decreased both ITVs and ISQ readings. This may be due to the fact that they inserted the implants in the mandible which has different mechanical properties than the maxilla. Moreover, in his study the implants were inserted in patients which have many variabilities in between them that could affect ITVs (35).

Effect of drilling protocol on peri-implant area post loading:

In all loading points the SG near the pontic area recorded the highest compressive microstrain strain values compared to the other 3 SG located around each implant regardless of implant drilling protocol or length. In light of this result, it may be expected that bone loss maybe initiated at this area. A recent study by De Souza Batista et al. in the year 2017, investigated using 3 unit-FPD supported on 2 or 3 implants with different configurations. When 2 implants were placed with a central pontic in between the FEA showed stress concentration in the cortical bone between the 2 implants meaning the implants were being pulled together. Furthermore, when comparing the microstrain in the same model the cortical bone on the distal side of the MI and the mesial side of DI had the highest strain when axially loaded. This result was consistent with the result of this study (36). As the load came closer to the implant, as in DCLP and MsCLP, the PIS around that implant increased. This increase could be explained by the fixed-fixed beam engineering equation with one-point load (Figure 6) and newtons third law " for every reaction there is an equal and opposite reaction". This also explain that when loading the middle connector forces on the MIs were slightly higher due to the fact that the molar is larger mesio-distally than the premolar i.e. shifting the forces more towards the MI (37). 


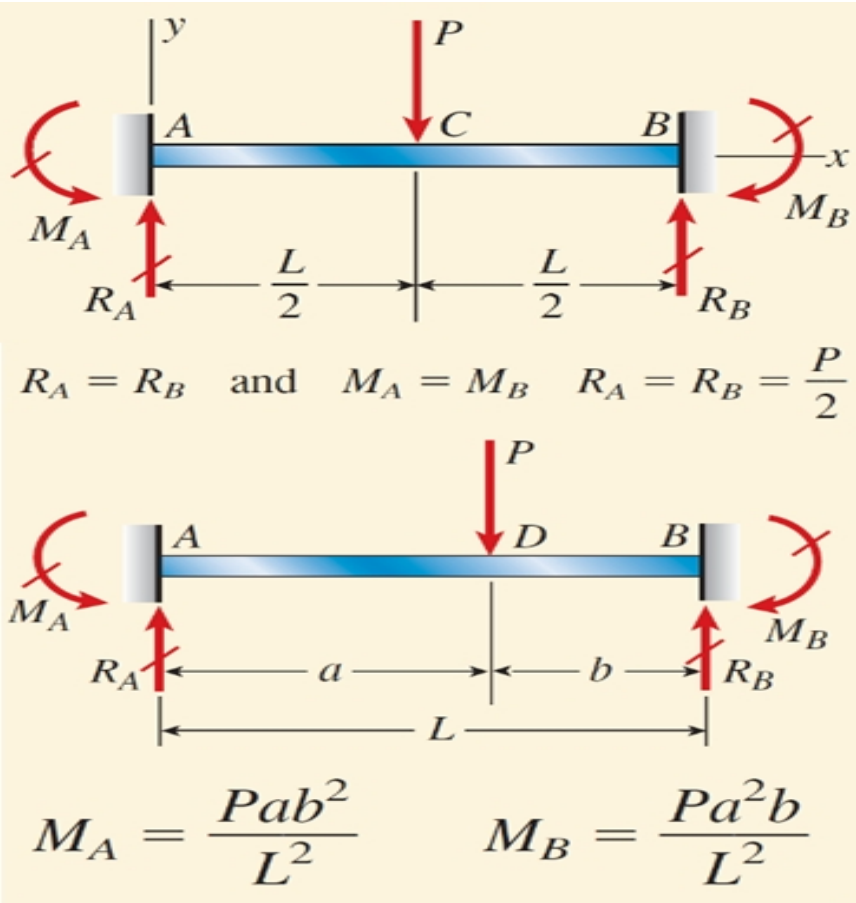

Figure 6 Fixed beams equation

As regards to the effect of ODP compared to CDP, the PIS strain in the ODP were significantly lower and this may be explained by the fact that the Densah drills are tapered in shape which is the same configuration as the implant shape therefore allowing more thread contact and lowering surface strain(27). Dos Santos et al. (2011), concluded that the use of tapered drills with tapered implant had higher IT than using cylindrical drills with cylindrical implants (38).

In our study, the maximum strain in the ODP group was $2642 \mathrm{~N}$ and $4484 \mathrm{~N}$ for CPD group at $800 \mathrm{~N}$. Taking into consideration the mechanical properties by Matin \& Burr in the year 1989 and later on by Frost in 2004 which suggested that pathological failure of the bone beyond $4000 \mu \varepsilon$ we can conclude that ODP did not exceed that number while the CPD group exceeded $(39,40)$.

The null hypothesis of the study was rejected as ODP showed significant decrease in PIS in comparison to CPD.

\section{CONCLUSIONS}

Within the limitations of this in vitro study, the following conclusions may be made:

1. Osseodensification drilling protocol increased insertion torque values and peri-implant insertion torque strain in comparison to conventional drilling protocol.

2. 4-unit screw retained monolithic full anatomy zirconium FPD can be used with osseodensification in posterior maxilla but with careful attention to occlusal load and direction.

3. Longer implant showed higher ISQ values but insignificant increase in insertion torque values and periimplant insertion torque strain in both groups.

4. Osseodensification decreased peri-implant strain in comparison to conventional protocol upon loading the FPD up to $800 \mathrm{~N}$.

5. Load position and magnitude on FPD directly affects the peri-implant strain.

\section{Conflict of interest}

The authors declare that they have no conflicts of interest.

The author(s) received no specific funding for this work.

\section{REFERENCES}

1. Elias CN. Factors Affecting the Success of Dental Implants: Instituto Militar de Engenharia, Biomaterials Laboratory Rio de Janeiro, RJ Brazil; 2011.

2. Trisi P, Berardini M, Falco A, Vulpiani MP. Effect of Implant Thread Geometry on Secondary Stability, Bone Density, and Bone-to-Implant Contact : A Biomechanical and Histological Analysis. 2015;24.

3. Santiago JF, Verri FR, Almeida DADF, De Souza Batista VE, Lemos CAA, Pellizzer EP. Finite element analysis on influence of implant surface treatments, connection and bone types. Materials Science and Engineering: C. 2016;63.

4. Tabassum A, Meijer GJ, Wolke JGC, Jansen JA. Influence of the surgical technique and surface roughness on the primary stability of an implant in artificial bone with a density equivalent to maxillary bone: a laboratory study. Clin Oral Implants Res. 2009;20.

5. Summers RB. A new concept in maxillary implant surgery: the osteotome technique. Compendium (Newtown, Pa). 1994;15.

6. Rao P, Gill A. Primary stability: The password of implant integration. 2012;2.

7. Lee E, Anitua E. Atraumatic ridge expansion and implant site preparation with motorized bone expanders. Pract Proced Aesthet Dent. 2006;18:17-22.

8. Di Stefano DA, Perrotti V, Greco GB, Cappucci C, Arosio $\mathrm{P}$, Piattelli A, et al. The effect of undersizing and tapping on bone to implant contact and implant primary stability: A histomorphometric study on bovine ribs. J Advanced Prosthodontics. 2018;10.

9. Bashutski JD, D'Silva NJ, Wang H-L. Implant Compression Necrosis: Current Understanding and Case Report. 2009;80.

10. Degidi M, Daprile G, Piattelli A. Influence of Stepped Osteotomy on Primary Stability of Implants Inserted in Low-Density Bone Sites: An In Vitro Study. The International $\mathrm{J}$ of oral \& maxillofacial implants. 2017;32:37-41.

11.Huwais SJ, MI, US), inventor; Huwais salah, assignee. Fluted osteotome and surgical method for use. United States2012.

12.Huwais SJIP. Enhancing implant stability with osseodensification: A two year follow up. 2015;8:28-34.

13.Huwais S, Meyer EG. A Novel Osseous Densification Approach in Implant Osteotomy Preparation to Increase Biomechanical Primary Stability, Bone Mineral Density, and Bone-to-Implant Contact. The International $\mathrm{J}$ of oral \& maxillofacial implants. 2017;32:27-36.

14.Pai U, Rodrigues S, Talreja K, Mundathaje M. Osseodensification \&\#8211; A novel approach in implant dentistry. 2018;18:196-200. 
15.Faverani LP, Barão VAR, Ramalho-Ferreira G, Delben JA, Ferreira MB, Garcia Júnior IR, et al. The influence of bone quality on the biomechanical behavior of full-arch implant-supported fixed prostheses. Materials Science and Engineering: C. 2014;37:164-70.

16.Muelas-Jiménez MI, Olmedo-Gaya MV, ManzanoMoreno FJ, Reyes-Botella C, Vallecillo-Capilla M. LongTerm Survival of Dental Implants with Different Prosthetic Loading Times in Healthy Patients: A 5-Year Retrospective Clinical Study. 2015.

17.Branemark P-I. Osseointegration and its experimental background. Journal of Prosthetic Dentistry. 1983;50:399-410.

18.Östman P-O, Hellman M, Wendelhag I, Sennerby L. Resonance frequency analysis measurements of implants at placement surgery. J International Journal of Prosthodontics. 2006;19.

19.Martinez H, Davarpanah M, Missika P, Celletti R, Lazzara R. Optimal implant stabilization in low density bone. 2001;12:423-32.

20.Cochran DL, Nummikoski PV, Schoolfield JD, Jones AA, Oates TW. A Prospective Multicenter 5-Year Radiographic Evaluation of Crestal Bone Levels Over Time in 596 Dental Implants Placed in 192 Patients. 2009;80:725-33.

21.F1839-08 A. Standard Specification for Rigid Polyurethane Foam for Use as a Standard Material for Testing Orthopaedic Devices and Instruments ASTM International, West Conshohocken, PA,(2016) [Available from: http://www.astm.org/cgi-bin/resolver.cgi?F1839.

22.Li B, Aspden RM. Composition and Mechanical Properties of Cancellous Bone from the Femoral Head of Patients with Osteoporosis or Osteoarthritis. J of Bone and Mineral Research. 1997;12:641-51.

23.Sawbones [cited 2019 30/9/2019]. Available from: https://www.sawbones.com/biomechanical/materialselection/.

24.Comuzzi L, Tumedei M, Pontes AE, Piattelli A, Iezzi GJIJoER, Health P. Primary Stability of Dental Implants in Low-Density (10 and 20 pcf) Polyurethane Foam Blocks: Conical vs Cylindrical Implants. 2020;17:2617.

25.Wang L, Wu Y, Perez KC, Hyman S, Brunski JB, Tulu U, et al. Effects of Condensation on Peri-implant Bone Density and Remodeling. J Dental Research. 2017;96:413-20.

26.Toia M, Stocchero M, Cecchinato F, Corra E, Jimbo R, Cecchinato D. Clinical Considerations of Adapted Drilling Protocol by Bone Quality Perception. The International journal of oral \& maxillofacial implants. 2017;32:1288-95.

27.Gehrke SA, Guirado JLC, Bettach R, Fabbro MD, Martínez CP-A, Shibli JA. Evaluation of the insertion torque, implant stability quotient and drilled hole quality for different drill design: an in vitro Investigation. 2016.

28.Farag AM, Lopez CD, Neiva RF, Tovar N, Witek L, Coelho PG. Atemporal osseointegration: Early biomechanical stability through osseodensification. J Orthopaedic Research®. 2018;36:2516-23.
29.Slete FB, Olin P, Prasad H. Histomorphometric comparison of 3 osteotomy techniques. J Implant dentistry. 2018;27:424-8.

30.Block J, Matalon S, Tanase G, Ormianer Z. Effect of Restorative Configurations and Occlusal Schemes on Strain Levels in Bone Surrounding Implants. 2017;26:574-80.

31.Bataineh AB, Al-Dakes AM. The influence of length of implant on primary stability: An in vitro study using resonance frequency analysis. J Clin Exp Dent. 2017;9.

32.Hsu J-T, Wu AY-J, Fuh L-J, Huang H-L. Effects of implant length and 3D bone-to-implant contact on initial stabilities of dental implant: a microcomputed tomography study. BMC Oral Health. 2017;17.

33.Shiffler K, Lee D, Rowan M, Aghaloo T, Pi-Anfruns J, Moy PK. Effect of length, diameter, intraoral location on implant stability. Oral Surgery, Oral Medicine, Oral Pathology and Oral Radiology. 2016;122:e193-e8.

34.Nappo A, Rengo C, Pantaleo G, Spagnuolo G, Ferrari M. Influence of Implant Dimensions and Position on Implant Stability: A Prospective Clinical Study in Maxilla Using Resonance Frequency Analysis. Applied Sciences. 2019;9:860.

35.Sarfaraz H, Johri S, Sucheta P, Rao S. Study to assess the relationship between insertion torque value and implant stability quotient and its influence on timing of functional implant loading. J Indian Prosthodont Soc. 2018;18:139-46.

36.De Souza Batista VE, Verri FR, Almeida DADF, Santiago Junior JF, Lemos CAA, Pellizzer EP. Finite element analysis of implant-supported prosthesis with pontic and cantilever in the posterior maxilla. Computer Methods in Biomechanics and Biomedical Engineering. 2017;20:663-70.

37.Gere JM, Goodno BJ. Mechanics of Materials. 7th ed: Cengage Learning; 2008. 1022 p.

38.Dos Santos MV, Elias CN, Cavalcanti Lima JH. The Effects of Superficial Roughness and Design on the Primary Stability of Dental Implants. Clinical Implant Dentistry and Related Research. 2011;13:215-23.

39.Martin R, Burr D. The microscopic structure of bone. Structure, function, and adaptation of compact bone: Raven Press, New York, NY, USA; 1989.

40. Frost HM. A 2003 update of bone physiology and Wolff's Law for clinicians. J The Angle Orthodontist. 2004;74:3-15. 